\title{
Post-Exercise Airway Narrowing in Healthy Primary School Children
}

\author{
FRANÇOIS MARCHAL, CYRIL SCHWEITZER, FRÉDÉRIQUE WERTS, LAN THI THUY VU, BRUNO DEMOULIN,
} AND YEN THI NGUYEN

\begin{abstract}
Service d'Explorations Fonctionnelles Pédiatriques [F.M., C.S., F.W.], Hôpital d'Enfants, Centre Hospitalier Universitaire de Nancy, Vandoeuvre les Nancy, 54500, France; Laboratoire de Physiologie [F.M., B.D.], Faculté de Médecine, Vandoeuvre les Nancy, 54505, France; Department of Pediatrics [Y.T.N.], National Children Hospital, Ha Noi, Vietnam; and Department of Pediatrics [L.T.T.V.], Saint Paul Hospital, Ha Noi, Vietnam
\end{abstract}

\begin{abstract}
Changes in lung function after exercise in healthy primary school children have mostly been described in field studies. More complete description and insight into relevant mechanisms may be provided in lung function laboratory. The aim was to describe airway caliber and response to deep inhalation (DI) after exercise in healthy primary school children. Respiratory resistance (Rrs) by the forced oscillation technique and spirometry were measured before and after exercise in 50 healthy primary school children. The Rrs response to DI was assessed in 31 subjects, assuming a significantly larger decrease in Rrs after exercise would attest relief of exerciseinduced airway smooth muscle contraction. Measurements were taken before, $5 \mathrm{~min}$ (E5) and $15 \mathrm{~min}$ (E15) after exercise. Significantly larger Rrs and lower forced expiratory volume in $0.5 \mathrm{~s}$ were observed at E5 versus baseline or E15 $(p<0.05)$. DI induced significant decrease in Rrs $(p=0.01)$ that was not different between E5 and baseline. Healthy primary school children exhibit changes in Rrs and spirometry after exercise indicating small but significant airway narrowing. The response to DI similar at baseline and E5 suggests airway narrowing from hyperemia in the bronchial wall rather than airway smooth muscle constriction. (Pediatr Res 63: 328-331, 2008)
\end{abstract}

$\mathrm{T}_{\mathrm{s}}^{\mathrm{h}}$ here is considerable interest in assessing the airway response to exercise in children because of the clinical impact of exercise triggered asthma attacks $(1,2)$. Field studies in unselected primary school children have described the distribution of lung function changes after exercise $(3,4)$ or tested prevalence of exercise induced bronchoconstriction (EIB) in relation with respiratory symptoms $(5,6)$. In these studies, the response was expressed as largest fall in forced expiratory volume in $1 \mathrm{~s}$ (FEV1) within 10-15 min of exercise cessation $(3,4)$ or considered positive when peak expiratory flow decreased $15 \%$ or more $(5,6)$. To the best of our knowledge, whether significant change in airway caliber occurs in healthy children during the recovery from exercise has not been documented. In the context of a lung function laboratory, the airway response to exercise may be characterized more

Received May 4, 2007; accepted October 20, 2007.

Correspondence: François Marchal, M.D., Laboratoire de Physiologie, Faculte de Medecine UHP Nancy, Avenue de la Foret de Haye, Vandoeuvre les Nancy, 54505, France; e-mail: f.marchal@chu-nancy.fr

Supported by grants CPRC, University Hospital of Nancy, and EA 3450 from Ministry for Research, France. thoroughly and indications obtained relative to potential mechanisms. The respiratory resistance (Rrs) measured by the forced oscillation technique (FOT) is considered a good proxy to airway caliber above a few herz (7). It is particularly relevant to pediatric studies, as it requires minimal cooperation. Forced expiratory volume in $0.5 \mathrm{~s}$ (FEV0.5) has been suggested more sensitive than FEV1 to airway caliber in young children because of their high rate of lung emptying (8). FEV0.5 could also prove useful in school children who are known to have higher FEV1 to forced vital capacity ratio than adults. In addition, the tracking of time variations of Rrs has the potential to identifying mechanisms of bronchoconstriction by assessing change induced by a deep inhalation (DI) $(9,10)$. When acute bronchoconstriction has been pharmacologically induced in a context of normal baseline lung function, DI induces significant bronchial smooth muscle relaxation (11-13). As a corollary, significant reduction of Rrs in response to DI after exercise could be taken as an indicator to reversal of exercise induced airway smooth muscle contraction. Because EIB may result from airway smooth muscle contraction and/or airway hyperemia $(14,15)$, the response to DI could possibly contribute to identify the mechanism involved. For instance, asthmatic children have recently been identified to exhibit significant bronchodilation by DI during mild EIB (10), suggesting airway smooth muscle contraction as significant factor. On the other hand, exercise induced airway narrowing in healthy children may not necessarily reflect the same mechanism.

The aims of the study were thus (1) to characterize the airway response to exercise in healthy primary school children and (2) to assess the bronchomotor effect of DI after exercise. The hypothesis is that healthy children do not show significant bronchoconstriction after exercise. If the hypothesis is wrong, however, an increase in airway smooth muscle tone by exercise should be attested by a larger bronchodilation by DI after exercise.

\section{MATERIALS AND METHODS}

Subjects. Healthy children volunteered from two local public schools. Medical history, physical examination, and ECG were taken. Criteria for

Abbreviations: DI, deep inhalation; E5, E15, 5 and 15 min after exercise, respectively; EIB, exercise induced bronchoconstriction; F, breathing frequency; FEV0.5, forced expiratory volume in $0.5 \mathrm{~s} ; \mathbf{F E V 1}$, forced expiratory volume in $1 \mathrm{~s}$; FOT, forced oscillation technique; Rrs, respiratory resistance; VE, minute ventilation; VT, tidal volume 
inclusion were no history of asthma or chronic respiratory symptoms or heart disease; no acute respiratory tract infection during the past month; normal physical examination and ECG. Written informed consent was obtained from the child and his/her parents. The protocol was reviewed and approved by the local committee for human subject protection in biomedical research (CPPRB, CHU de Nancy, Nancy, France).

Measurements. A custom-made pneumatic belt was placed around the child's waist and connected to a differential pressure transducer (Data Instruments DCXL01DN, Ventest Mobile, Soderel Médical, Nancy, France), the output of which was displayed on a computer screen. The visual feedback was used to monitor tidal volume and coach the child in breathing regularly and taking a deep breath on demand only.

Respiratory resistance. The measuring system (Pulmosfor, SEFAM, France) was in conformity with recommendations issued by a task force from the European Respiratory Society (7). Pressure was applied at $12 \mathrm{~Hz}$ around the child's head to minimize upper airway wall motion. One advantage of the head generator technique is that it allows using such range of excitation frequency without majoring the upper airway artifact (16), thereby improving the signal to noise ratio and the ability to track Rrs time course (10). Airflow, tidal volume (VT) and Rrs were displayed immediately after each acquisition to allow visual inspection and selection of data, which were stored on disk. VT, breathing frequency (F) and minute ventilation (VE) were averaged and mean Rrs was computed in inspiration to minimize the contribution of upper airway (17). In what follows, Rrs refers to this value.

Deep inhalation. The DI maneuver was performed while Rrs was continuously measured. After 4-6 tidal breaths, the child performed a quick full inspiration and resumed normal breathing, although Rrs measurement was pursued for up to $40-50 \mathrm{~s}$. The end-point set to validate the DI was an inspired volume $\geq 40 \%$ predicted forced vital capacity (18). Tracings were inspected by eye and those showing insufficient DI or irregular breathing were not retained for analysis. Rrs was averaged breath by breath and the lowest Rrs from the 3 respiratory cycles after the DI was compared with the mean of the $4-5$ breaths before DI.

Spirometry. Forced spirometry was performed as previously described (10). An electronic flowmeter with computer animation programs (Masterscope Erich Jaeger GmbH, Wuertzburg, Germany) was used. The forced expiratory maneuver was explained to the child and trials were performed. Forced expiratory maneuvers were repeated until at least two curves displaying early rise to peak flow followed by regular decrease throughout expiration were obtained, with forced vital capacities within $10 \%$ of each other. This was usually obtained within five trials. The best curve was selected as the one with the highest sum forced vital capacity + FEV1. FEV1 and FEV0.5 were analyzed.

Exercise. Exercise challenge was performed according to recommendations (19) and consisted in a 6 min-run on a treadmill $(\mathrm{h} / \mathrm{p} / \mathrm{cosmos}$ mercury med 4.0, Nussdorf - Traunstein, Germany) in a climate room where absolute humidity was kept $<10 \mathrm{mg} / \mathrm{L}$. Air temperature and water content were measured daily using a thermo-hygrometer (Thermometer Hygrometer Delta Ohm, HD 8901 Padua, Italy). Heart rate was monitored using a heart rate monitor (Polar B1, Helsinki, Finland). The end-point was to increase cardiac frequency to about $80 \%$ of predicted maximum within the first 2 min and maintain this value throughout the test by adjusting the treadmill speed and slope.

Protocol. Breathing pattern was continuously monitored throughout Rrs measurement and assessment of effect of DI. Following $1 \mathrm{~min}$ regular breathing assessed from the pneumatic belt, the child was connected to the FOT apparatus and an acquisition of respiratory pressure and flow was started during tidal breathing for 30-40 $\mathrm{s}$. This was followed by another acquisition lasting 50-60 s during which the effect of DI was assessed. Spirometry was invariably measured after Rrs to avoid the bronchomotor effect of the forced vital capacity maneuver. Duplicate Rrs and spirometry were obtained about 10 min apart at baseline and will be referred to measurements $\mathrm{A}$ and $\mathrm{B}$. Exercise was then performed. Measurements were repeated as above, 5 and 15 min following cessation of exercise (E5, E15, respectively).

Data analysis. An analysis of variance for repeated measurements was used to assess the effect of exercise and DI (Statview software, Abacus Concepts Inc., Berkeley, CA). Data are expressed as mean \pm SEM since the interest is with general rather than individual characteristics. A difference was considered statistically significant at $p<0.05$.

\section{RESULTS}

A total of 50 healthy children (27 girls) were included. The characteristics of the study population are reported in Table 1. On study day, ambient temperature and air-water content were respectively $13.1 \pm 0.2^{\circ} \mathrm{C}$ and $5.5 \pm 0.2 \mathrm{mg} / \mathrm{L}$. Maximal heart rate achieved during exercise was $178 \pm 1.5$ beat $/ \mathrm{min}$.
Spirometry at E5 in one child and Rrs at E15 in another are missing for technical reasons. A proper DI maneuver could be obtained and interpreted at baseline, E5 and E15 in 31 children. The reasons for failure to obtain interpretable data on DI were irregular breathing $(n=9)$, insufficient DI after exercise $(n=2)$ or at any stage $(n=8)$.

Baseline. VE, VT, and $\mathrm{F}$ were all found to be significantly larger at A compared with B $(p<0.01$, Table 2). Spirometry and FOT data are reported in Table 3 . There was no significant difference in Rrs, FEV1, or FEV0.5 between A and B. However, because high ventilation could have impacted on Rrs at

Table 1. Characteristics of 50 healthy children

\begin{tabular}{lcccc}
\hline & Age $(\mathrm{y})$ & $\begin{array}{c}\text { Height } \\
(\mathrm{cm})\end{array}$ & $\begin{array}{c}\text { FVC } \\
(\%)^{*}\end{array}$ & $\begin{array}{c}\text { FEV1 } \\
(\%)^{*}\end{array}$ \\
\hline Mean \pm SEM & $8.3 \pm 0.2$ & $132 \pm 1.5$ & $100 \pm 2$ & $101 \pm 2$ \\
Range & $6-11$ & $113-155$ & $74-127$ & $74-133$ \\
\hline
\end{tabular}

FVC, forced vital capacity; FEV1, forced expiratory volume in $1 \mathrm{~s}$.

* Predicted from Ref. (18).

Table 2. Ventilation in 50 children

\begin{tabular}{lccc}
\hline & VE & & \\
& $(\mathrm{L} / \mathrm{min})$ & $\mathrm{VT}(\mathrm{L})$ & $\mathrm{F}(\mathrm{L})$ \\
\hline $\mathrm{A}$ & $9.2 \pm 0.5^{*}$ & $0.40 \pm 0.02 *$ & $24 \pm 1 \dagger$ \\
& $5.5-23.4$ & $0.22-0.91$ & $8-41$ \\
$\mathrm{~B}$ & $7.8 \pm 0.3$ & $0.36 \pm 0.01$ & $22 \pm 1$ \\
& $4.2-14.8$ & $0.20-0.67$ & $7-39$ \\
E5 & $8.7 \pm 0.3 \ddagger$ & $0.40 \pm 0.02 \S$ & $22 \pm 1$ \\
& $5.6-20.6$ & $0.22-0.79$ & $9-34$ \\
E15I & $7.5 \pm 0.2 \|$ & $0.36 \pm 0.01 \|$ & $22 \pm 1$ \\
& $4.7-12.9$ & $0.22-0.76$ & $10-32$ \\
\hline
\end{tabular}

Data are mean \pm SE and range.

A, B, measurements at baseline; E5, E15, 5 and 15 min following cessation of exercise, respectively; VE, minute ventilation; VT, tidal volume; F, breathing frequency.

$* p<0.005$ vs. B.

$\dagger p=0.01 v s$. B.

$\ddagger p=0.002$ vs. B.

$\S p<0.0001$ vs. B.

II $n=49$.

$\| p \leq 0.0001 v s$. E5.

Table 3. Respiratory resistance and spirometry in 50 children

\begin{tabular}{cccc}
\hline & Rrs & & \\
& $(\mathrm{hPa} \cdot \mathrm{s} / \mathrm{L})$ & FEV1 $(\mathrm{L})$ & FEV0.5 $(\mathrm{L})$ \\
\hline A & $7.4 \pm 0.3$ & $1.87 \pm 0.06$ & $1.48 \pm 0.05$ \\
& $3.6-12.9$ & $1.11-2.87$ & $0.82-2.23$ \\
$\mathrm{~B}$ & $7.1 \pm 0.3$ & $1.87 \pm 0.06$ & $1.47 \pm 0.05$ \\
& $3.3-12.8$ & $1.10-2.82$ & $0.80-2.17$ \\
E5 & $7.5 \pm 0.3^{*}$ & $1.84 \pm 0.06 \dagger$ & $1.44 \pm 0.04 \dagger+$ \\
& $3.5-13.8$ & $1.09-2.82$ & $0.82-2.09$ \\
E15 & $6.8 \pm 0.3 \dagger \S$ & $1.88 \pm 0.06$ I & $1.49 \pm 0.05 \|$ \\
& $3.2-11.0$ & $1.11-2.72$ & $0.82-2.07$ \\
\hline
\end{tabular}

Data are mean \pm SE and range.

$\mathrm{A}$ and $\mathrm{B}$, measurements at baseline; Rrs, respiratory resistance; FEV1, forced expiratory volume in $1 \mathrm{~s}$; FEV0.5, forced expiratory volume in $0.5 \mathrm{~s}$.

$\dagger n=49$.

$* p=0.0007 v s$. B

$\ddagger p=0.02$ vs. B.

$\S p<0.0001 v s$. E5.

$\mathbb{I} p=0.04 v s . \mathrm{E} 5$.

$\| p=0.0005$ vs. E5. 
baseline A, post-exercise Rrs was compared with B. For clarity, the same reference was taken to assess post-exercise spirometry.

Exercise. $\mathrm{VE}_{\mathrm{E} 5}$ was significantly larger than $\mathrm{VE}_{\mathrm{B}}(p=$ $0.002)$ or $\mathrm{VE}_{\mathrm{E} 15}(p=0.0001$, Table 2$)$, as a result of $\mathrm{VT}_{\mathrm{E} 5}$ being significantly larger than $\mathrm{VT}_{\mathrm{B}}$ or $\mathrm{VT}_{\mathrm{E} 15}(p<0.0001$, Table 2). On the other hand, there was no significant difference among $\mathrm{F}_{\mathrm{B}}, \mathrm{F}_{\mathrm{E} 5}$, or $\mathrm{F}_{\mathrm{E} 15}$ (Table 2). The data on airway response to exercise are summarized in Table 3. Rrs was found to be significantly larger at E5 compared with B ( $p=$ $0.0007)$ or E15 $(p<0.0001)$. FEV0.5 was significantly lower at $\mathrm{E} 5$ than either $\mathrm{B}(p=0.02)$ or $\mathrm{E} 15(p=0.0005)$. In addition, FEV1 was significantly lower at E5 than E15 ( $p=$ 0.04). The difference between B and E15 did not reach statistical significance for any parameter, although the difference between E5 and E15 appeared more statistically significant than between E5 and B. In summary, there was a significant decrease in airway caliber $5 \mathrm{~min}$ after exercise that was most readily shown by Rrs and FEV0.5.

Deep inhalation. The volume of the DI was not different at $\mathrm{A}(1.21 \pm 0.06 \mathrm{~L}), \mathrm{B}(1.23 \pm 0.06 \mathrm{~L}), \mathrm{E} 5(1.23 \pm 0.05 \mathrm{~L})$, and E15 $(1.24 \pm 0.06 \mathrm{~L})$. The usual effect was a small decrease in Rrs, lasting a few breathing cycles. Overall, the ANOVA showed significantly lower value after DI (Fig. 1). The lack of significant interaction between DI and test condition $(p=0.5)$ indicated similar effect of DI before and after exercise.

\section{DISCUSSION}

This study demonstrates small and transient but significant airway narrowing during the recovery from a short run in healthy primary school children. More specifically, a major finding is the larger Rrs and lower FEV0.5 observed at E5. The decrease in airway caliber after exercise is however not associated with more bronchodilation by DI.

Most available studies in healthy children involve peak expiratory flow or FEV1 with the objective to establish criteria to define EIB in asthma rather than to systematically describe changes in airway caliber in healthy children at different times after exercise $(3,4,6,20,21)$. We are unaware of prior detailed assessment of the airway response to exercise in children, confronting FOT, spirometry and response to DI, using stan-

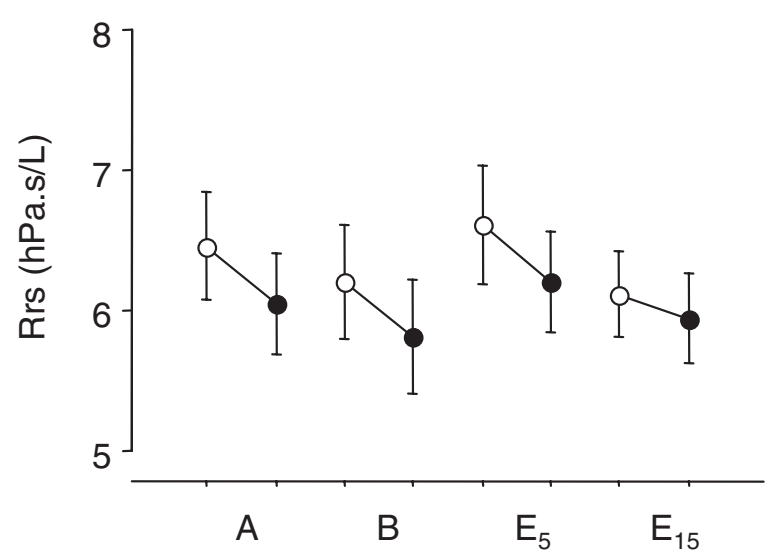

Figure 1. Rrs is significantly decreased by deep inhalation at all stages $(p=$ 0.01 ). The effect is not different between baseline and exercise. Open and closed circles: before and after deep inhalation, respectively. dardized challenge intensity and controlled ambient air thermo-hygrometry, both determinant factors of EIB $(19,22)$. In the current sample of healthy school-aged volunteers, the success rate for lung function testing was high because spirometry from only one child at E15 and FOT from another at E5 could not be retained. In contrast, the success rate was lower when assessing the effects of DI. It was thus experienced that the necessary maneuver including a full inspiration in-between few breaths of regular tidal breathing was more difficult to obtain than standard FOT and spirometry. The FOT study by Lenney and Milner did not demonstrate any significant change in Rrs after a free run in control preschool children (23). Extending the current study to this age range would certainly be of great interest but may be limited by the preschool child's ability to cooperate with the DI maneuver.

Ventilation was significantly elevated at first baseline, as a result of an increase in both F and VT, probably induced by some degree of apprehension in these naïve children. The hyperventilation might have been responsible for more turbulent flow possibly impacting on Rrs (24). Of note, there was a slight residual hyperventilation in the early recovery from exercise, which was related to an increase in VT but not F. The mechanisms for the hyperventilation appear thus different between $\mathrm{A}$ and $\mathrm{E} 5$. In addition, the VE difference between $\mathrm{E}_{5}$ and $\mathrm{B}$ was less than between A and B. Estimation of airway caliber at $\mathrm{B}$ was thus taken as baseline. $\operatorname{Rrs}_{\mathrm{E} 5}$ was clearly shown to be significantly elevated versus $\mathrm{B}$ and there was concordant decrease in FEV0.5 at E5. The same trend was found with FEV1 but statistical difference was not reached. In fact, the lung empties faster in preschool children than at adult age (8) and the current data further suggest that FEV0.5 may be more sensitive to change in airway caliber than FEV1 in school children as well. The observed airway narrowing - in contrast with asthmatics during EIB (10)—was not associated with lung distension, as suggested by volume of DI (25) which remained basically unchanged throughout. The fact that the parameters were back to baseline at E15 indicates the change in airway caliber was short-lived.

Small but significant decrease in Rrs was demonstrated after DI, before and after exercise (Fig. 1). In healthy children at rest, the response has been documented using spirometry (26-28), in keeping with our baseline FOT data. The increase in airway caliber after DI has been assigned to more energy loss in the conducting airways than in parenchyma during stretching. As a result, the bronchial caliber is increased for some time after the DI (12). A major factor governing energy dissipation into the airway wall during stretching relates to the degree of airway smooth muscle contraction (29). An increase in airway caliber by DI is therefore taken as an indicator to bronchial smooth muscle relaxation and is particularly noticeable when bronchoconstriction has been acutely induced by methacholine or histamine inhalation $(30,31)$. Altogether, the current findings on the effects of DI at baseline are consistent with significant airway smooth muscle tone in children, as indicated in other studies by the effect of beta-adrenergic agonists $(32,33)$. Recently, asthmatic children were demonstrated to exhibit large bronchodilation by DI during mild EIB, an effect attributed to transient reversal of airway smooth 
muscle contraction (10). In contrast, in the current study, the significant Rrs decrease by DI was similar at E5 and baseline (Fig. 1). The meaning of this lack of change might be difficult to interpret as any negative finding. However, the significant point here is not that effect of DI is unchanged by exercise per se but rather that this finding contrasts with the evidence of significant airway narrowing by exercise. In other words, the post-exercise reduction in airway caliber was not associated with airway smooth muscle contraction. Significant bronchial hyperemia and/or airway wall edema has been indicated as factors to post-exercise airway narrowing $(14,15)$. Of considerable interest is the observation that during fluid loading of the bronchial wall by rapid saline infusion in healthy adult humans, FEV1 decreases and Rrs increases while the bronchodilation by DI, assessed before and after methacholine, remains unaltered (34). Therefore, the current characteristics of decrease in airway caliber observed during recovery from a short run in healthy children are consistent with similar mechanism, where the airways response to stretch is expected to be unaltered, e.g., transient airway wall hyperemia.

Finally, it is worth mentioning that the statistical difference between E5 and E15 was more significant than between E5 and B for any parameter. This, together with the apparently smaller amplitude of response to DI at E15 (Fig. 1) could suggest relaxation of airway smooth muscle at E15. DI repetition could have resulted in some degree of bronchoprotection toward the end of the study, as previously documented in different experimental set-ups in healthy adults (35). Significant release of catecholamine in the blood stream has been documented in exercising adult subjects (36) but we are unaware of such data in healthy children during the recovery from exercise. Firmer evidence would be needed to ascertain the indication of increased in airway caliber at E15 compared with E5 in healthy children.

It is concluded that healthy children show small but definite airway narrowing after exercise, attested by increase in Rrs and decrease in FEV0.5. The bronchodilatory effect of DI is unchanged - in contrast to asthmatic children-indicating no significant airway smooth muscle contraction. Rather, it is suggested that reduction in airway caliber results from transient bronchial wall hyperemia.

Acknowledgment. The authors gratefully acknowledge the valuable contribution of Dr. Anne Frisoni (Rectorat de Nancy, Académie de Nancy Metz) in recruiting the subjects, Children and their parents, teachers, and administrators of public schools "Louis Pergaud, Laxou" and "Brabois Vandoeuvre". The authors also thank Dr. François Marçon and staff for expert cardiologic support, Claude Bonabel-Choné, and Sylvie Méline for technical assistance.

\section{REFERENCES}

1. Carlsen KH, Carlsen KC 2002 Exercise-induced asthma. Pediatr Respir Rev 3:154-160

2. Godfrey S 1999 Clinical and physiological features. In McFadden E (ed) Exercise Induced Asthma. Marcel Dekker, New York, Basel, pp 11-45

3. Backer V, Dirksen A, Bach-Mortensen N, Hansen KK, Laursen EM, Wendelboe D 1991 The distribution of bronchial responsiveness to histamine and exercise in 527 children and adolescents. J Allergy Clin Immunol 88:68-76

4. Haby MM, Peat JK, Mellis CM, Anderson SD, Woolcock AJ 1995 An exercise challenge for epidemiological studies of childhood asthma: validity and repeatability. Eur Respir J 8:729-736
5. De Baets F, Bodart E, Dramaix-Wilmet M, Van Daele S, de Bilderling G, Masset S, Vermeire P, Michel O 2005 Exercise-induced respiratory symptoms are poor predictors of bronchoconstriction. Pediatr Pulmonol 39:301-305

6. Jones CO, Qureshi S, Rona RJ, Chinn S 1996 Exercise-induced bronchoconstriction by ethnicity and presence of asthma in British nine year olds. Thorax 51:1134-1136

7. Oostveen E, MacLeod D, Lorino H, Farre R, Hantos Z, Desager K, Marchal F 2003 The forced oscillation technique in clinical practice: methodology, recommendations and future developments. Eur Respir J 22:1026-1041

8. Aurora P, Stocks J, Oliver C, Saunders C, Castle R, Chaziparasidis G, Bush A 2004 Quality control for spirometry in preschool children with and without lung disease. Am J Respir Crit Care Med 169:1152-1159

9. Jensen A, Atileh H, Suki B, Ingenito EP, Lutchen KR 2001 Selected contribution: airway caliber in healthy and asthmatic subjects: effects of bronchial challenge and deep inspirations. J Appl Physiol 91:506-515; discussion 504-505

10. Schweitzer C, Vu LT, Nguyen YT, Chone C, Demoulin B, Marchal F 2006 Estimation of the bronchodilatory effect of deep inhalation after a free run in children. Eur Respir J 28:89-95

11. Wang L, Pare PD 2003 Deep inspiration and airway smooth muscle adaptation to length change. Respir Physiol Neurobiol 137:169-178

12. Brusasco V, Pellegrino R 2003 Complexity of factors modulating airway narrowing in vivo: relevance to assessment of airway hyperresponsiveness. J Appl Physiol 95:1305-1313

13. Pellegrino R, Sterk PJ, Sont JK, Brusasco V 1998 Assessing the effect of deep inhalation on airway calibre: a novel approach to lung function in bronchial asthma and COPD. Eur Respir J 12:1219-1227

14. Anderson SD, Kippelen P 2005 Exercise-induced bronchoconstriction: pathogenesis. Curr Allergy Asthma Rep 5:116-122

15. McFadden E (ed) 1999 Exercise-induced asthma as a vascular phenomenon. In Exercise Induced Asthma. Marcel Dekker, New York, Basel, pp 115-135

16. Peslin R, Duvivier C, Didelon J, Gallina C 1985 Respiratory impedance measured with head generator to minimize upper airway shunt. J Appl Physiol 59:1790-1795

17. Schweitzer C, Chone C, Marchal F 2003 Influence of data filtering on reliability of respiratory impedance and derived parameters in children. Pediatr Pulmonol 36:502-508

18. Knudson RJ, Lebowitz MD, Holberg CJ, Burrows B 1983 Changes in the normal maximal expiratory flow-volume curve with growth and aging. Am Rev Respir Dis 127:725-734

19. Anderson SD, Brannan JD 2003 Methods for "indirect" challenge tests including exercise, eucapnic voluntary hyperpnea, and hypertonic aerosols. Clin Rev Allergy Immunol 24:27-54

20. Godfrey S, Springer C, Bar-Yishay E, Avital A 1999 Cut-off points defining normal and asthmatic bronchial reactivity to exercise and inhalation challenges in children and young adults. Eur Respir J 14:659-668

21. Riedler J, Reade T, Dalton M, Holst D, Robertson C 1994 Hypertonic saline challenge in an epidemiologic survey of asthma in children. Am J Respir Crit Care Med 150:1632-1639

22. Carlsen KH, Engh G, Mork M 2000 Exercise-induced bronchoconstriction depends on exercise load. Respir Med 94:750-755

23. Lenney W, Milner AD 1978 Recurrent wheezing in the preschool child. Arch Dis Child 53:468-473

24. de Bisschop C, Pichon A, Guenard H, Denjean A 2003 Accounting for flow dependence of respiratory resistance during exercise. Respir Physiol Neurobiol 136:65-76

25. Duranti R, Filippelli M, Bianchi R, Romagnoli I, Pellegrino R, Brusasco V, Scano G 2002 Inspiratory capacity and decrease in lung hyperinflation with albuterol in COPD. Chest 122:2009-2014

26. Assefa D, Amin N, Dozor AJ 2004 Effect of deep inspiration on airway caliber in children with asthma. Pediatr Pulmonol 38:406-412

27. Landau LI, Morgan W, McCoy KS, Taussig LM 1993 Gender related differences in airway tone in children. Pediatr Pulmonol 16:31-35

28. O'Connor GT, Sparrow D, Demolles D, Dockery D, Raizenne M, Fay M, Ingram RH, Speizer FE 2000 Maximal and partial expiratory flow rates in a population sample of 10- to 11-yr-old schoolchildren. Effect of volume history and relation to asthma and maternal smoking. Am J Respir Crit Care Med 162:436-439

29. Sasaki H, Hoppin FG Jr 1979 Hysteresis of contracted airway smooth muscle. J Appl Physiol 47:1251-1262

30. Brusasco V, Pellegrino R, Violante B, Crimi E 1992 Relationship between quasistatic pulmonary hysteresis and maximal airway narrowing in humans. J Appl Physiol 72:2075-2080

31. Burns CB, Taylor WR, Ingram RH Jr 1985 Effects of deep inhalation in asthma: relative airway and parenchymal hysteresis. J Appl Physiol 59:1590-1596

32. Beydon N, Amsallem F, Bellet M, Boule M, Chaussain M, Denjean A, Matran R, Wuyam B, Alberti C, Gaultier C 2002 Pre/postbronchodilator interrupter resistance values in healthy young children. Am J Respir Crit Care Med 165:1388-1394

33. Nielsen KG, Bisgaard H 2001 Discriminative capacity of bronchodilator response measured with three different lung function techniques in asthmatic and healthy children aged 2 to 5 years. Am J Respir Crit Care Med 164:554-559

34. Pellegrino R, Dellaca R, Macklem PT, Aliverti A, Bertini S, Lotti P, Agostoni P, Locatelli A, Brusasco V 2003 Effects of rapid saline infusion on lung mechanics and airway responsiveness in humans. J Appl Physiol 95:728-734

35. Brusasco V, Crimi E, Barisione G, Spanevello A, Rodarte JR, Pellegrino R 1999 Airway responsiveness to methacholine: effects of deep inhalations and airway inflammation. J Appl Physiol 87:567-573

36. Gilbert IA, Lenner KA, McFadden ER Jr 1988 Sympathoadrenal response to repetitive exercise in normal and asthmatic subjects. J Appl Physiol 64:2667-2674 